\title{
Effec $t$ of Freeze-Thaw Cycles on Lipid Oxidation and Myowater in Broiler Chickens
}

\section{-Author(s)}

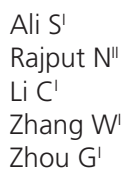

Key Laboratory of Meat Processing and Quality Control, College of Food Science and Technology;

" College of Animal Science and Technology, Nanjing Agricultural University, Nanjing 210095, P. R. China

\section{-Mail Address}

Corresponding author e-mail address Guanghong Zhou

Key Laboratory of Meat Processing and Quality Control, Nanjing Agricultural University, Nanjing, Jiangsu, 210095 P. R. China.

Phone: (+86) 2584395376

Email: zhouguanghongnjau@gmail.com

\section{EKeywords}

Freeze-thaw cycles, chicken meat, oxidation, drip loss, color.

\section{ABSTRACT}

The present study was carried out to investigate the influence of freezing-thawing cycles $(0,2,4$ and 6$)$ on lipid oxidation and myowater contents and distribution. Nine replicates of chicken breast meat samples were used for each cycle. Lipid oxidation was determined by measuring peroxide value, and malondialdehyde (MDA) concentrations, which reflect thiobarbituric acid reactive substance (TBARS). Color was determined with a digital colorimeter. Muscle moisture contents were determined by drip loss and thawing loss, water holding capacity, and nuclear magnetic resonance (NMR). The results showed that, as the number of freeze-thaw cycles increased, meat redness decreased and MDA and peroxide values increased. Drip loss and thawing loss tended to decreasing as the number of freeze-thaw cycles increased. Water holding capacity also decreased as a function of increasing freeze-thaw cycles. NMR relaxometry profile showed freeze-thaw cycles change the water distribution of meat subjected to multiple freeze-thaw cycles. In conclusion, multiple freezing and thawing rate $(6$ cycles) increased lipid oxidation, decreased myowater, and impaired the color of chicken meat.

\section{INTRODUCTION}

Freezing is an excellent method to maintain the quality of meat and to keep it fresh for a long time (Sung et al., 2013). It is frequently applied to control the meat supply in the market. Furthermore, this preservation method provides a great logistical advantage required for the export of meat (Fagan et al., 2003). In general, the quality of frozen meat is closely associated with the freezing and thawing processes. Freezing and thawing rate collectively have a vital role in tissue damage and water loss due to the small ice crystals formation (freezing) and drip loss (thawing). Meat or products are subject to damage by physical and chemical changes during thawing (Kalichevsky et al., 1995).

Freezing may deteriorate meat quality (Vieira et al., 2009). During freezing, ice crystals are formed between the fibers and within the fibers, physically damaging the ultra-structure of the meat. Major threat to the quality of frozen meat is the reduction of water-holding capacity (WHC), which is manifested as loss of exudate (drip loss) upon thawing. Drip loss has a direct impact on protein functionality, leading to increasing water losses due to a weaker interaction protein and water. (Xiong, 2000; Reznick et al., 1992) The ice crystals that are formed pull water from the intracellular spaces into the intercellular spaces, leading to excessive moisture loss during thawing, which influences the sensory profile and the tenderness of meat (Ngapo et al., 1999). Multiple freeze-thaw cycles increase the loss of muscle moisture, as the damage to the ultrastructure of the meat fibers does not allow uptake of moisture into the intracellular spaces, leading to thawing loss, while freezing deteriorates meat quality due to osmotic removal of water, mechanical damage due 
to ice crystal formation, and lipid and protein oxidation (Benjakul et al., 2001; Xiong, 2000), thawing cause meat discoloration, thawing and cooking loss, and lipid oxidation (Xia et al., 2009). However, the main threat to the quality of frozen meat is the decrease of waterholding capacity (WHC), which is manifested as a loss of exudate (drip) upon thawing. Drip loss has a direct impact on meat weight and reduces its tenderness and the overall eating quality, and all these factors seriously affect its commercial value (Jeremiah, 1996).

Moreover, during thawing, foods are subject to damage by chemical and physical changes and by the action of microorganisms (Kalichevsky et al., 1995). Generally, after thawing, leftover food may be put in the freezer again. When this food is thawed again, quality changes occur and people's health may be seriously affected (Hallier et al., 2007). Especially in restaurants and meat markets, these freeze-thaw cycles may be repeated several times. It is very important to determine the quality changes that occur during multiple freezethawing treatments (Baygar et al., 2012), and therefore, optimum thawing procedures should be of concern of food technologists (Kalichevsky et al., 1995). The most common and widely preferred method of thawing frozen food is placing it in the refrigerator.

An important factor plays an essential role in the appearance and acceptability of frozen meat is its color. The color of foods during cold storage is affected by lipid oxidation and pigment degradation (Diaset al., 1994).

A number of scientific studies have examined the effect of freezing rate on drip loss (Huff-Lonergan \& Lonergan, 2005). In contrast, the effect of thawing rate on meat drip loss has received much less attention. Given the economic consequences of high drip loss for meat processors and its possible quality implications for consumers, this issue needs to be addressed. Most of the studies on freeze-thaw cycle (FT) effects on meat have focused on fish and red meats (Fernández et al., 2007; Tateo et al., 2007).

Our literature review showed that very few studies have investigated the effect of freeze-thaw cycles on chicken meat and there is a need to further examine the influence of multiple Freeze-thaw cycles on lipid oxidation, muscles water and color of chicken meat.

\section{MATERIALS AND METHODS}

\section{Sampling}

About $250 \mathrm{~g}$ of breast meat per replicate was randomly selected and nine samples (totaling 63 samples for seven cycles) were used for the determination of the evaluated parameters. Each sample was cut in cubes ( $4 \times 3 \times 1$ inches) and the visible fat and connective tissue were removed. Immediately after measuring meat $\mathrm{pH}$ and color, all samples were packed in polyethylene bags and transported to the National Center of Meat Quality and Safety Control of Nanjing. All samples were kept at $-20^{\circ} \mathrm{C}$ and subjected to zero (fresh), two, four, and six freeze-thaw cycles. After each cycle, all frozen samples were allowed to thaw at $4^{\circ} \mathrm{C}$ in a refrigerator for 12 hours. The thawed samples were maintained at $4^{\circ} \mathrm{C}$ during handling. The samples were grinded to obtain homogeneity before analysis.

\section{pH and Muscle color}

The $\mathrm{pH}$ values of meat samples were measured using a digital $\mathrm{pH}$ meter. Meat color was determined according to lightness $\left(L^{*}\right)$, redness $\left(a^{*}\right)$, and yellowness $\left(b^{*}\right)$ values using a Konica Minolta colorimeter CR-400.

\section{Determination of lipid oxidation}

Thiobarbituric acid (TBA) reacts with malondialdehyde (MDA) to form a stable pink color, which is an indicator of lipid peroxidation. Thiobarbituric acid reactive substances (TBARS) were measured spectrophotometrically at $532 \mathrm{~nm}$. TBARS levels were determined using a corresponding diagnostic chemical kit (Nanjing Jiancheng Bioengineering Institute, Nanjing, China) as described by Zhang et al. (2009). MDA values were expressed as $\mathrm{nmol} / \mathrm{mg}$ protein

\section{Drip loss}

Drip loss was determined as described by Honikel, (1987) with modification. The sample $(7 \mathrm{~g} \pm 0.5)$ was weighed and then hung inside an airtight plastic bag on a hook under the lid. After storage for $24 \mathrm{~h}$ at 4 ${ }^{\circ} \mathrm{C}$, the sample was again weighed. Drip loss, as a percentage sample weight, was calculated as:

Drip loss \% = initial weight of sample- final weight of sample /initial weight of sample $\times 100$

\section{Thawing loss}

Thawing loss was calculated as a percentage of weight loss before and after thawing. Thawed samples (1.0-cm thick and $70 \pm 5 \mathrm{~g}$ ) were cut perpendicularly to muscle direction. Then all samples were hanged in vertical chiller for 12 hours and the liquid was collected in cups places under the hangers. Thawing loss of the thawed sample was calculated according to the formula (AOAC, 1995):

Thawing loss $\%=$ frozen sample weight - thawed sample weight / frozen sample weight $\times 100$ 


\section{Water-Holding Capacity (WHC)}

The WHC was measured using the method described by Li et al. (2012). Briefly, the raw meat sample (approximately $2 \mathrm{~g}$ ) was placed between a preweighed 18 Whatman (No. 1) filter paper and pressed under a force of $343 \mathrm{~N}$ for 5 min using a compression machine (YYW-2, Nanjing Soil Instrument, China). Pressing loss was calculated as a percentage of weight loss before and after compression of meat, and expressed as:

Expressible water $(\%)=$ (initial sample weight - final sample weight) / initial sample weight $\times 100$

\section{Nuclear magnetic resonance}

The NMR can be used to determine the physicochemical conditions of water. Low-field NMR relaxation measurements were performed on a Niumag Benchtop Pulsed NMR Analyzer PQ001 operating at a resonance frequency for protons of $22.6 \mathrm{MHz}$ as described by Han et al. (2009).

Approximately $1 \mathrm{~g}$ of sample $(1 \times 1 \times 1 \mathrm{~cm})$ was placed in the NMR tube. Spin-spin relaxation time, $T_{2^{\prime}}$ was measured using the Carr-Purcell-MeiboomGill sequence. The $T_{2}$ measurements were made with a $\tau$-value (time between $90^{\circ}$ and $180^{\circ}$ pulse) of $150 \mu$ s. Data from 4000 echoes acquired as 12 scan repetitions. The repetition time between subsequent scans was 4000 ms. Each of the measurements were performed in triplicate. Post-processing of NMR $T_{2}$ data, distributed according to exponential fitting of CPMG (Carr-Purcell-Meiboom-Gill) decay curves, were performed by the Multi-Exp Inv Analysis software.

\section{Statistical Analysis}

Statistical analyses were performed using SPSS software (SPSS 15.0 K for Windows, Chicago, IL), and all data were expressed as means \pm standard error of the mean (SEM) values. Data were submitted to oneway analysis of variance. Significant differences among means of the nine replicates were compared by Tukey's test at $p<0.05$.

\section{RESULTS AND DISCUSSION}

\section{Color}

The lightness $\left(L^{*}\right)$ value increased from 43.3 to $46.57(p<0.05)$ during 0 to 6 freeze-thaw cycles. A cycle-dependent increasing trend in $L^{*}$ and $b^{*}$ values and decreasing trend for $a^{*}$ value was observed (Table 1). The $L^{*}$ value was significantly higher by $1.93 \%$ and $2.02 \%$, while the $b^{*}$ was $14.89 \%$ and $22.61 \%$ for C4 and C6, and the a* value was significantly lower by $19.30 \%, 24.67 \%$ and $27.81 \%$ for C2, C4 and $\mathrm{C} 6$ compared with $\mathrm{C} 0$, respectively. Similarly, the $b$ * value increase was concurrent and simultaneous with increased lipid oxidation in freeze-thaw cycles (Thanonkaew et al., 2006).

Table 1 - Impact of multiple freeze-thaw cycles on the color of chicken breast muscle.

\begin{tabular}{lllll}
\hline \multirow{2}{*}{ Item } & \multicolumn{4}{c}{ Cycles } \\
\cline { 2 - 5 } & $\mathrm{C} 0$ & $\mathrm{C} 2$ & $\mathrm{C} 4$ & $\mathrm{C} 6$ \\
\hline $\mathrm{L}^{*}$ & $50.18 \pm 2.2$ & $50.05 \pm 2.8$ & $51.15 \pm 2.6$ & $51.23 \pm 2.3$ \\
$\mathrm{a}^{*}$ & $3.55 \pm 0.9$ & $2.98 \pm 0.4$ & $2.85 \pm 0.3$ & $2.78 \pm 0.5$ \\
$\mathrm{~b}^{*}$ & $11.02 \pm 2.3^{\mathrm{ab}}$ & $10.17 \pm 3.7^{\mathrm{b}}$ & $12.66 \pm 2.2^{\mathrm{ab}}$ & $13.51 \pm 3.5^{\mathrm{a}}$ \\
\hline abc Means with different letters are significantly different $(\mathrm{p}<0.05) \cdot(\mathrm{n}=9)$
\end{tabular}

It was noticed that the reduction in the $a^{*}$ value (red color) and the increase in $L^{*}$ and $b^{*}$ values (yellow color) of the chicken meat breasts was associated with an increase in TBARS production. Similar findings were reported by Yuand Jong (2005), who also observed that the decrease in redness and the increase in yellowness were related with the increase in lipid oxidation of cooked turkey muscle.

Furthermore, the reduced redness and increased yellowness caused by the freeze-thaw cycles were may have been due to the production of metmyoglobin. Xia et al. (2009) reported that the decrease in redness and the increase in yellowness in freeze-thaw cycles of pork loin was due to the formation of metmyoglobin. In addition, Jung et al. (2003) observed that the decrease in beef redness and changes in yellowness may be associated with the oxidation of myoglobin to metmyoglobin, which turns meat color brown.

\section{Malondialdehyde}

Freeze-thaw cycles increased $(p<0.05)$ meat MDA levels, which were $27 \%, 76 \%$, and $206 \%$ higher for C2, C4 and C6 compared with CO (Figure 1). The present findings showed that the samples processed in different freeze-thaw cycles produced significantly different TBARS values.

Normally, the oxidation is accelerated in freezethaw cycles due to loss of integrity of the muscle system caused by repeated freeze-thawing. Cells may be damaged by the formation of ice crystals, as well as by the release of oxidative enzymes and prooxidants, resulting in lipid oxidation and consequent increase in water loss and weaker protein gels (Xiong, 2000; Reznick et al., 1992; Benjakul \& Bauer, 2001). 


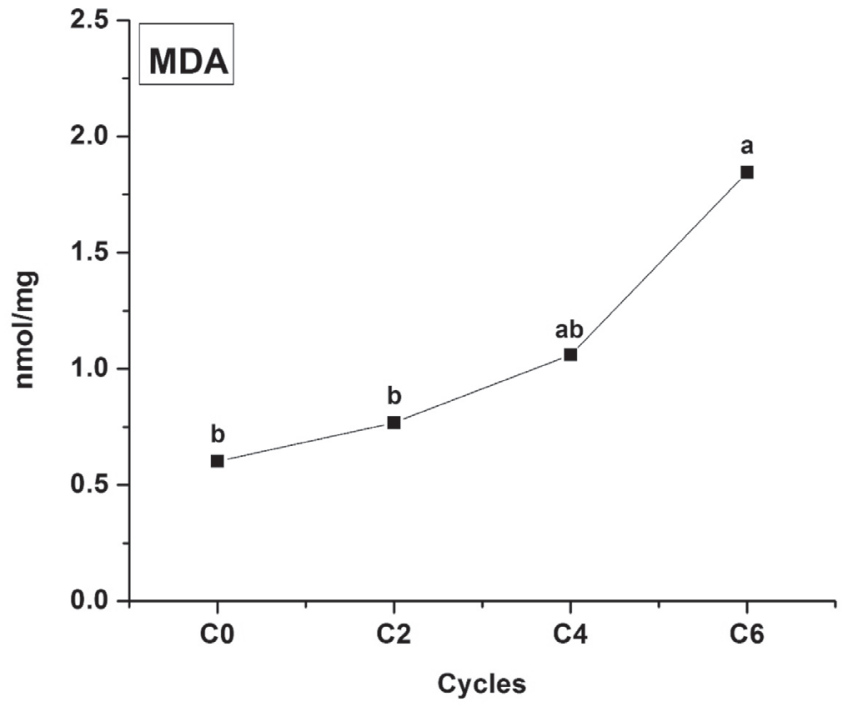

Figure 1 - Impact of freeze-thaw cycles on the MDA levels (TBARS value) of chicken breast muscle Unit $=\mathrm{nmol} / \mathrm{mg}$ protein; abc Means with different letters are significantly different $(p<0.05, n=9)$.

Furthermore, lipid oxidation tends to increase with time of frozen storage (Thanonkaew et al., 2006). In addition, free radicals enhance lipid oxidation, which, in turn, increases the levels of malondialdehyde (MDA), which is the end product of lipid peroxidation (Jung et al., 2012).

\section{Nuclear Magnetic Resonance}

The $T_{21}$ relaxation profiles demonstrated three water states in the muscle, with $T_{2 b}$ representing hydration water, and $T_{21}$ and $T_{22}$ representing immobilized and bulk water, respectively (Figure 2 ).

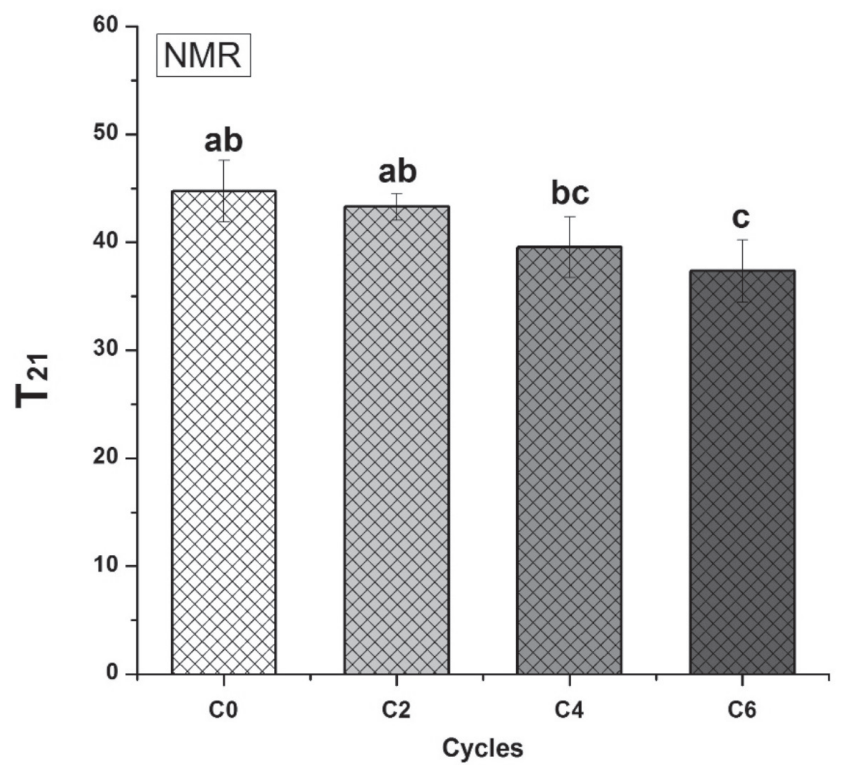

Figure 2 - Distribution of proton T2 relaxation times measured in a chicken sample at $25^{\circ} \mathrm{C}$. Three populations at approximately $1-5 \mathrm{~ms}$ (T2b), 35-50 ms (T22) and 150-250 ms (T21) were detected.
The NMR performed during freeze-thaw cycles showed that the $T_{21}$ values of fresh samples were reduced from 44.73 to 37.35 from the first to sixth freeze-thaw cycle. There was a significant decrease of $3.33 \%$ in the second cycle, of $13.15 \%$ in the fourth cycle (C4), and of $19.75 \%$ decreased in the sixth cycle (C6) compared with fresh sample (Figure 3). In meats, any changes in the $T_{21}$ time constant indicates changes in the structural organization of myofibrillar water. The results show that there was a significant reduction of myowater in the myofibrillar matrix, which can be related to shrinkage of the muscle fibers and mobilization of water to extracellular space. $T_{21}$ has been reported to alter with the multiple freeze-thaw cycles (Li et al., 2012). Similarly, T22 values decreased in the first three to four cycles and then increased, but the differences were not statistically different.

Proportion

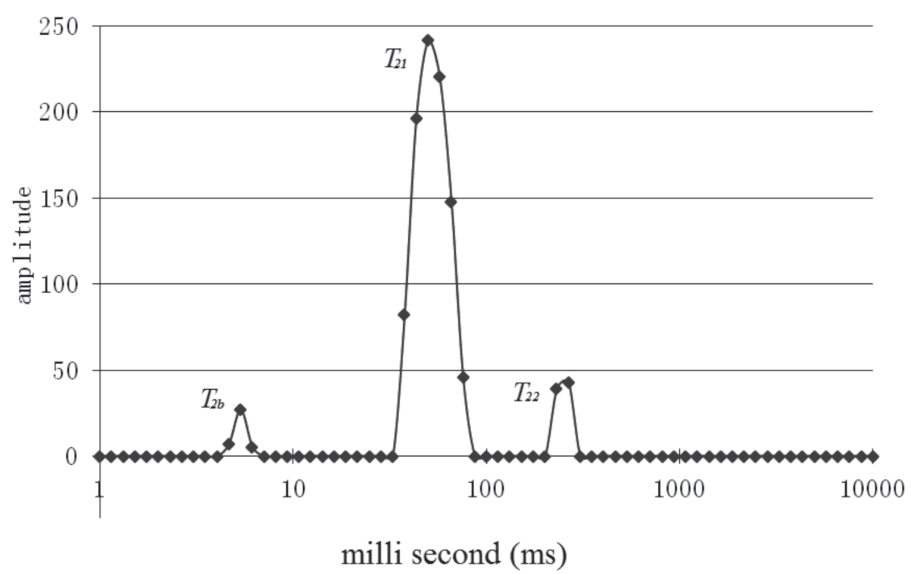

Figure 3-Impact of freeze-thaw cycles on the changes in proton T21 relaxation times measured in chicken breast samples; abcd Means with different letters are significantly different $(p<0.05)$.

\section{Drip loss, thawing loss, and water holding capacity}

The results showed that drip loss significantly increased by $40.31 \%$ in C2, $52.91 \%$ in C4, and $61.00 \%$ in C6 compared with C0. Thawing loss also increased by $42.55 \%, 57.03 \%$, and $64.76 \%$ in C2, C4 and C6, respectively, compared with the fresh samples (Figure 4). Most muscle water is trapped between the myofibrils and the cell membrane, especially the myofibrillar protein that holds and stores water, which plays a vital role in promoting the waterholding capacity of the muscle tissue (Huff-Lonergan \& Steven, 2005). Lipid oxidation is believed to cause changes in protein structures and therefore, to alter the water-holding capacity of the muscle (Lagerstedt et al., 2008). 


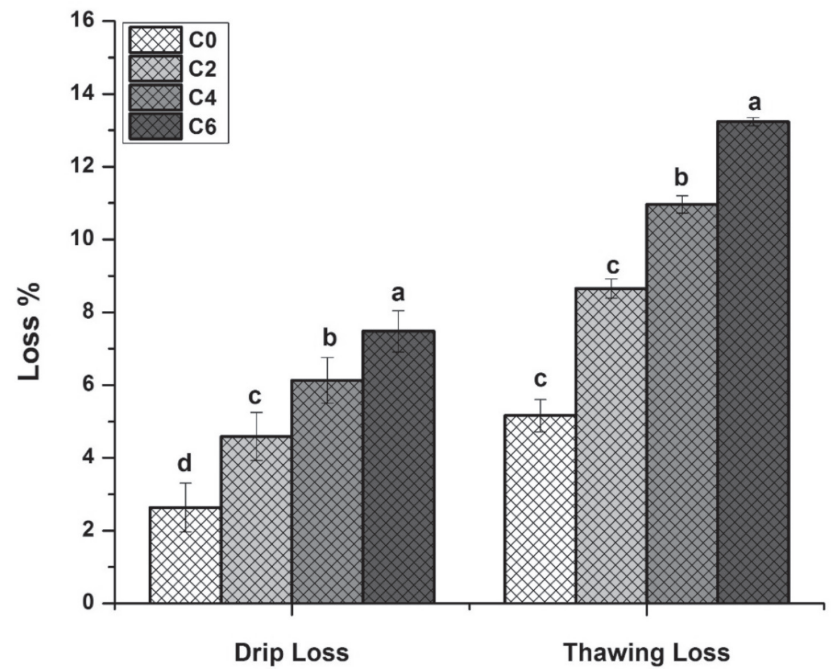

Figure 4 - Impact of freeze-thaw cycles on the drip and thawing loss of chicken breast muscle; abc Means with different letters are significantly different $(p<0.05, n=9)$.

The frequent melting during thawing and restructuring of ice crystals during freezing in a number of freeze-thaw conditions was evidently harmful to muscle tissues by mechanically damaging the cell membranes and the loss of the water-holding capacity. The freeze-thaw cycle is the main contributor for the reduction in WHC, and unacceptably low WHC cause considerable product damage (Ali et al., 2015).

Similarly, a cycle-dependent decreasing trend was recorded for WHC, which decreased by 2.39\%, 5.19\%, and $8.80 \%$ in C2, C4 and C6 (Figure 5), respectively, compared with fresh samples (C0). Drip loss during thawing indicate a reduction of water-holding capacity

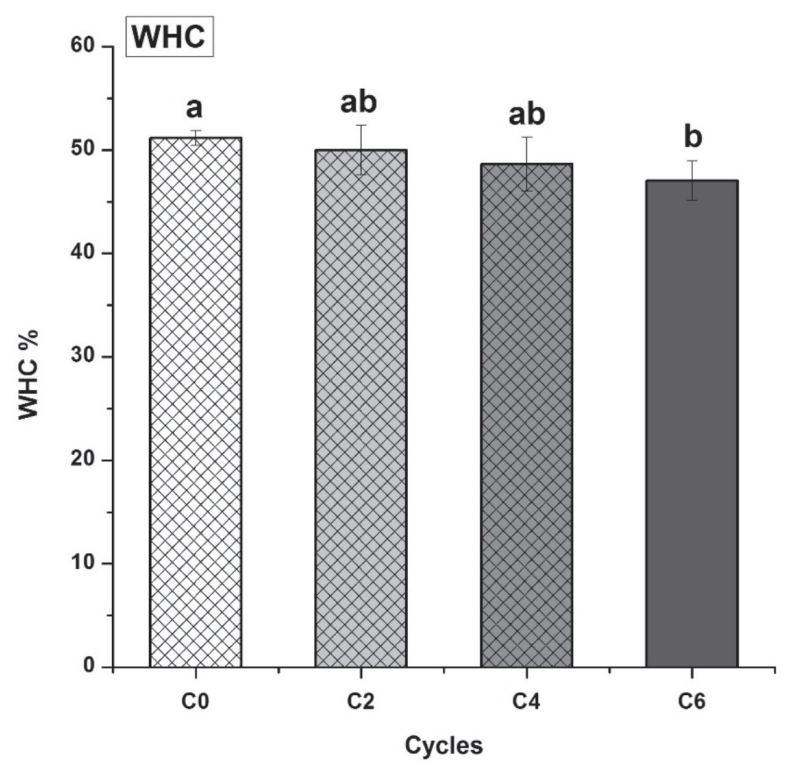

Figure $\mathbf{5}$ - Effects of freeze-thaw cycles on water holding capacity (WHC) of chicken breast muscle; $n=9$; abcd Means with different letters are significantly different $(p<0.05)$.
(WHC). Moisture loss has a direct impact on meat weight and reduces its overall eating quality, and all of these factors seriously affect its commercial value. One of the causes of lower meat acceptability is drip loss, possibly due to the loss of essential ingredients, e.g. various amino acids or nucleotides.

When the thawing rate was increased, drip loss increased and water holding capacity decreased. This result is consistent with Xia et al. (2009), who had previously established a correlation between pork water content and WHC, as well as a correlation between an increase in water loss and a decrease in WHC in the muscle.

Based on present findings, it was concluded that multiple freeze-thaw (six cycles) increased lipid oxidation, decreased myowater, and damaged the color of chicken meat.

\section{REFERENCES}

Ali S, Zhang WG, Rajput N, Khan AA, Li CB, Zhou GH. Effect of multiple freeze-thaw cycles on the quality of chicken breast meat. Food Chemistry 2015;173:808-814.

AOAC - Association of the Official Analytical Chemists. Offcial method of analysis. 16th ed. Washington; 1995.

Baygar T, Alparslan Y, Çakl S. Effects of multiple freezing and refrigerator thawing cycles on the quality changes of sea bass (Dicentrarchus labrax). Iranian Journal of Fisheries Science 2012;12:289-300.

Benjakul S, Bauer F. Biochemical and physicochemical changes in catfish (Silurus glanis Linne) muscle as influenced by different freeze-thaw cycles. Food Chemistry 2012;72:207-217

Benjakul S, Visessanguan W, Ishizaki S, Tanaka M. Differences in gelatin characteristics of natural actomyosin from two species of bigeye smapper, Priacanthus tayenus and Priacanthus macracanthus. Journal Food Science 2001;66:1311-1318.

Dias J, Nunes ML, Mendes RR. Effect of frozen storage on the chemical and physical properties of black and silver scabbardfish. Journal of Science Food Agriculture 1994;66:327-335.

Fagan JD, Gormley TR, Mhuircheartaigh MU. Effect of freeze-chilling, in comparison with fresh, chilling and freezing, on some quality parameters of raw whiting, mackerel and salmon portions. Lebensmittel Wissenschaft and Technologie 2003;36:647-655.

Fernández PP, Sanz PD, Molina-Garcí AD, Otero L, Guignon B, Vaudagna S. Conventional freezing plus high pressure-low temperature treatment: Physical properties, microbial quality and storage stability of beef meat. Meat Science 2007;77:616-625.

Hallier A, Chevallier S, Serot T, Prost C. Freezing-thawing effects on the colour and texture of European catfish flesh. International Journal of Food Science Technology 2007;43:1253-1262.

Han M, Zhang Y, Fei Y, Xu X, Zhou G. Effect of microbial transglutaminase on NMR relaxometery and microstructure of pork myofibrillar protein gel. European Food Research Technology 2009;228:665-670.

Honikel KO. How to measure the water-holding capacity of meat? Recommendation of standardized methods. In: Tarrant PV, Eikelenboom 
G, Monin G, editors. Evaluation and control of meat quality in pigs. Dordrecht: Martinus Nijhoo; 1987. p.129-142.

Huff-Lonergan E, Lonergan SM. Mechanisms of water-holding capacity of meat: the role of postmortem biochemical and structural changes. Meat Science 2005;71:194-204.

Jeremiah LE. Freezing effects on food quality. New York: CRC Press; 1996

Kalichevsky MT, Knorr D, Lillford PJ. Potential food applications of high pressure effects on ice-water transitions. Trends of Food Science Technology 1995;6:253-258

Jung EK, Clark RM, Park Y, Lee J, Fernandez ML. Lutein decreases oxidative stress and inflammation in liver and eyes of guinea pigs fed a hypercholesterolemic diet. Nutrition Research and Practice 2012;6:113119.

Jung S, Ghoul M, Lamballerie-Anton M. Influence of high pressure on the color and microbial quality of beef meat. (Lebensmittel-Wissenschaft \& Technologie). Food Science and Technology 2003;36:625-631.

Lagerstedt A, Enfalt L, Johansson L, Lundstrom K. Effect of freezing on sensory quality, shear force and water loss in beef $\mathrm{M}$. longissimus dorsi. Meat Science 2008;80:457-461.

Li CB, Liu D, Zhou GH, Xu XL, Qi J, Shi P, et al. Meat quality and cooking attributes of thawed pork with different low field NMR T21. Meat Science 2012;92:79-83.

Ngapo TM, Babare IH, Reynolds J. Freezing and thawing rate effects on drip loss from samples of pork. Meat Science 1999;53:149-158.

Reznick AZ, Witt E, Matsumoto M, Packer L. Vitamin E inhibits protein oxidation in skeletal muscle of resting and exercised rats. Biochemical and Biophysical Research Communications 1992;189:801-806.
Sung SH, Bae YS, Oh SH. Possibility of instrumental differentiation of duck breast meat with different processing and storage conditions. Korean Journal of Food Science Analysis 2013;33:96-102.

Tateo A, Palo PD, Quaglia NC, Centoducati P. Some qualitative and chromatic aspects of thawed buffalo (Bubalus bubalis) meat. Meat Science 2007;76:352-358.

Thanonkaew A, Benjakul S, Visessanguan W. The effect of metal ions on lipid oxidation, color and physicochemical properties of cuttlefish (Sepia pharaoni) subjected to multiple freeze-thaw cycles. Food Chemistry 2006;95:591-599.

Vieira C, Diaz MY, Martínez B. Effect of frozen storage conditions (temperature and length of storage) on microbial and sensory quality of rustic crossbred beef at different states of aging. Meat Science 2009:83:398-404

Xia X, Kong B, Liu Q, Liu J. Physicochemical change and protein oxidation in porcine longissimus dorsi as influenced by different freeze-thaw cycles. Meat Science 2009;83:239-245.

Xiong YL. Protein oxidation and implication for muscle food quality. In: Decker EA, Faustman CL, Lopez-Bote CJ, editors. Antioxidants in muscle foods. New York: John Wiley and Sons; 2000. p.85-111.

Yu LH, Lee ES, Jong JY. Effects of thawing temperature on the physicochemical properties of pre-rigor frozen chicken breast and leg muscles. Meat Science 2005;71:375-382.

Zhang GF, Yang ZB, Wang Y, Yang WR, Jiang SZ, Gai GS. Effects of ginger root (Zingiber officinale) processed to different particle sizes on growth performance, antioxidant status, and serum metabolites of broiler chickens. Poultry Science 2009:88:2159-2166. 